\title{
16
}

\section{Capturing Music and Dance in an Archive: A Meditation on Imprisonment}

\author{
Adrienne L. Kaeppler
}

I contribute this chapter in honour of our dear colleague Stephen Wild, with whom I have worked on many projects over many years. In the early 1990s, Stephen was the section editor for Australia for the Garland Encyclopedia of World Music (Kaeppler and Love 1998) and wrote several important entries. In 1995 I served on the programme committee of the International Council for Traditional Music (ICTM) conference in Canberra and here I learned of, and admired, his immense knowledge of Australian music and dance, as well as his work with the community to host this complex event. Most important was our work together on the Board of ICTM, especially during the years when he was Secretary General and Vice President while I was President. Indeed, I don't know how I would have survived without him. An earlier version of this chapter was presented as the keynote for the symposium on archives organised by Stephen in Canberra in 2010, 'Tangible Records of the Intangible: Collecting Musical and Choreographic Culture in Oceania'. Stephen always invited us to 'think outside the box', so I hope that this chapter meets his criteria. 
I begin this chapter by asking a few sets of rhetorical questions-mainly to remind ourselves that we should continue to ask them. What are music and dance? Why do we want to capture them? How can we capture something intangible? How do we imprison what we have captured? How do we interrogate and use what we have captured? How can the captured be released from imprisonment and used for appropriate purposes?

Next I ask, what is an archive? According to the dictionary, an archive is 'a collection of historical documents or records providing information about a place, institution, or a group of people' (Oxford University Press 2002: 61). This raises a further set of questions. What is a collection? What or when is history? What kinds of documents or records should we save? Why do we want to keep this information? Who is going to use it, and for what purposes?

I will explore these questions with two case studies-a 1937 silent film on Tahitian dance and a 1960s film on Hawaiian dance performed by 'Iolani Luahine. The films will be interrogated for questions of access, preservation, and repatriation, as well as their uses for cultural identity and the study of changing aesthetics.

\section{What are music and dance?}

Music and dance are multifaceted phenomena that include, in addition to what we see and hear, the 'invisible' underlying systems of sound and movement recognised by specific cultures, the processes that produce both the system and the product, and the sociopolitical contexts in which they are embedded. In many societies there are no categories comparable to the Western concepts 'music' and/or 'dance'; thus analyses of sound and movement have been enlarged to encompass all structured sound and movement, including, but not limited to, those associated with religious and secular ritual, ceremony, entertainment, martial arts, sign languages, sports, and games. What these categories share is that they result from creative processes that manipulate (i.e. handle with skill) sounds and movements made by humans through time and space.

It is this larger conceptual category of 'structured sound and movement' that has been captured in archives and saved for future generations. Some categories of sound and movement may be further marked or elaborated 
culturally as 'music' (a specially marked or elaborated category of structured sound) and 'dance' (a specially marked or elaborated category of structured movement). Although many of us are devoted to musics and dances of the Pacific Islands, the musics and dances that we perform and study are not well known in many parts of the world. Indeed, only one Pacific Island performing genre was recognised by UNESCO as a Masterpiece of the Oral and Intangible Heritage of Humanity'Lakalaka of Tonga: Sung Speeches with Choreographed Movements'.

\section{Archiving performance, analysis, and emotion}

In the globalised world of the twenty-first century, what do we want to capture and imprison in an archive? How will the captured be preserved, documented, and used? How can they be released from prison? I believe that there are several important elements of intangible cultural heritage that should be captured and archived. I will focus on three of these: performance, analysis, and emotion.

The first important element is capturing performances by film/video, still photographs, and recorded sound. The capturing of performances in context is of high priority, as is the written documentation for the captured performances. Indeed, without written documentation performances are simply imprisoned.

A second important element is analysis of the performances. This needs to be done as research 'in the field' as 'participant observation' by music and dance researchers in conjunction with indigenous performers and researchers. The notes from these analyses need to be archived as well as any writings (published or not) about the content and context of performances. A description of the context for each performance needs to be collected and preliminary notation or notes, and analysis of structure, should begin in the field with the performers.

A third important element is what I will call 'emotion'. This would include attempting to understand aesthetic principles and emotions felt by dancers and audiences. This needs to be carried out by specialists from within and outside the culture, and extended to collecting oral histories of both performers and observers. 
In addition, and perhaps most important of all, is keeping the music and dance alive in the bodies and minds of indigenous performers, teachers, and students. The UNESCO Masterpieces programme has led the way in its insistence that 'masterpieces' should be 'constantly recreated', and by funding action plans that focus on preserving and using masterpieces in modern life, and not just as encounters with the past.

To develop some of these ideas, I will explore two case studies of specific events that were captured on film in 1937 and 1960, and my own associations and uses of these films.

\section{Tahitian dance film from 1937}

In 1974, after giving a paper called 'Polynesian Dance as Airport Art' at a combined conference of the Society for Ethnomusicology and Council on Research in Dance (published as Kaeppler 1977), Marian Van Tuyl Campbell asked me if I would like to have the film footage taken by her husband Dr Douglas Campbell in Tahiti in 1937, much of which was of dance. Marian Campbell, a Western dance historian and modern dance choreographer, was not interested in researching Polynesian dance herself, but hoped that the films would have 'archaeological interest' as background to my studies of Polynesian dance. Campbell gave these 16-mm silent films to Bishop Museum (where I was then employed). The collection consists of 350 feet of colour film and 375 feet of blackand-white film. ${ }^{1}$

On receiving the film, my question was, and is: how can archival film help us to understand not only music/dance, but how they are embedded in society? The short answer is that archival film is of no help at all, unless assistance of the people of the society depicted in the film is enlisted. An outsider viewing these silent films can describe and characterise the Tahitian movement system-for example, the importance of hand and arm movements; the upright torso and absence of shoulder movements; that the lower body movements are elaborated into complex motifs that combine hip rotations, sways, and tilts; and that the movements differ according to gender. With further analysis and knowledge of the music and poetry, an observer might be able to discern that the lower body

1 See Kaeppler (2002b). I repeat some of that essay here as the book in which it was published is probably not available to many researchers in the Pacific. 
movement motifs appear to be associated with the rhythmic dimensions of the music while the arm movements are concerned with conveying poetic allusions or telling stories.

But is this what we want to know well into the twenty-first century? We no longer want to simply analyse the sounds of musical performance or the movements of dance performances. Instead, analysing the social and political contexts of performance and the contemporary uses of older musical and dance forms for cultural and ethnic identity has become increasingly important. How, then, can archival resources assist in modern ethnomusicological enterprises? The first step is to enlist the help of the people recorded and/or filmed.

In order to enlist the help of Tahitians, in 1979 I took these 1937 films back to Tahiti, and in conjunction with my research, screened the films twice for Tahitian audiences. My aim at the time was to do an ethnohistoric study of Tahitian and Tuamotuan music and dance-a study that I never finished. I had previously done research in Tahiti in 1964, 1975, and 1976, especially with Tuamotuans living in Tahiti. In 1976, working with Kenneth Emory, we took to the Tuamotuans copies of wax cylinders that Emory and others had recorded in the 1920s and 1930s. The Tuamotuans were really not very interested and quickly tired of listening to the scratchy sound and difficult-to-understand texts. So, I was not very optimistic about screening silent dance films for Tahitians. Nevertheless, I booked a small theatre for two showings of the films. For the first screening, only a few specifically interested individuals attended, but word spread quickly and the second showing was well attended.

Forty-two years had passed since the films were made. Some of those depicted were still alive, and lamenting was heard for those who had passed on. Viewers told me about the dances performed-the dance genres, the performers, the leaders, and other relevant information. However, what really interested the Tahitians was that the films had been made at their important local festival-known at that time as Tiurai or the Fête Nationale, and now known as Heiva.

As the Campbell films captured dancing prepared for the fête in 1937, they are of specific interest in studying continuity and change in the dances themselves, as well as the aesthetics of presentation. One of the viewers in 1979 was a dance leader (ra'atira) from the island of Taha'a. He noted that the dances had really changed since 1937, and in his view, they should 'go back to the old way of doing the dances'. One of the 
dances performed by his group during the 1979 fête was an unusual dance featuring vigorous movements on tiered platforms (stands or steps). He was especially interested because this dance was performed in the 1937 film.

According to viewers of the films, the teacher of the 1937 tiered-platform dance was a man called Hio. They noted that the dance was called 'ote' $a$ paepae ('ote' $a$, a dance genre; paepae, platform), and that it was originally done by the people of the Patutoa area of Pape'ete. They described the skirt worn in the film as made of a kind of grass, rather than more (inner bark of the hibiscus), which is usually worn today. Further, they noted that the people of the Patutoa area came from the island of Atiu and other places in the Cook Islands in the 1930s and introduced this dance. Later the people from Fa'a'a copied the dance, and afterwards other groups did it as well—including Taha'a in 1979.

Another dance that interested the viewers in 1979 was a dance about catching whales called 'aparima tohorā ('aparima, a dance genre; tohorā, whale). One of the viewers, Paraurahi Moearuiti Tahake (b. 1914), said the dance was from Mataiea. Another dance leader, Parua from Paea, said the dance was also done by a group from Puna'auia. Also evident in the film footage is the variety of lower-body movement motifs for the men and the simplicity of the choreography. In 1937 the choreography was usually in one, two, or three lines performed in either a standing or crosslegged sitting position. By 1979, the choreography had become much more complex.

To my surprise, unlike the lack of interest that the Tuamotuans had shown in listening to the tapes made from the wax cylinders that $I$ had experienced in 1976, the Tahitian-dance audience was very interested.

The following year I moved to the Smithsonian Institution in Washington, DC, and unfortunately did not follow up on this promising beginning, nor did I continue my research on Tahitian and Tuamotuan music and dance. At one point, however, I did think that I would continue the research, and asked the Human Studies Film Archives at the Smithsonian to borrow the film from Bishop Museum to make a copy for me. The film was borrowed and a preservation copy of the film and two prints were made. These prints are now in Bishop Museum and in the Human Studies Film Archives of the Smithsonian. In addition, the Smithsonian made a video copy of the footage. The materials are now available in both Hawai' $i$ and Washington, 
DC, for anyone who wants to pursue this preliminary research. A video copy was made and sent to Tahiti. My 2002 article (Kaeppler 2002b) also accompanies the film. So, this film capturing dance in 1937, was at least partially released from prison in 1979/2002 and thereafter.

Next, I want to look briefly at archival photographs, by extending the 1937 films from Tahiti back in time to the tiered platform dance in the Cook Islands. In 1903, a group of people associated with the New Zealand Government toured the Cook Islands and other island groups in central and west Polynesia. An album of photographs taken during the tour includes depictions of the tiered-platform dance in Rarotonga, thus verifying what the Tahitians had told me. Helen Reeves Lawrence also confirmed the existence of tiered-platform dances in the Cook Islands. She informed me that, 'dancing on platforms was popular in the Cook Islands in the early 1900s. In the Southern Cooks, it was often performed on tiers of platforms, and on Manihiki it was performed on a single platform' (Helen Lawrence, pers. comm., 1993). ${ }^{2}$

\section{Hawaiian dance film from 1960-61}

I move now to a famous film of 'Iolani Luahine called Hula Hoolaulea: ${ }^{3}$ Traditional Dances of Hawaii, filmed by Francis Haar for the Honolulu Academy of Arts in 1960-61 (Haar 1961). I use this film in an effort to understand how the aesthetics of performance have changed during the past 50 years. I also explore how indigenous knowledge about volcanoes is perpetuated in dances about the volcano goddess Pele and her family, and how this knowledge is kept alive in contemporary performances of traditional stories (Kaeppler 2016). Using films, videos, and memories, I examine how sounds and movements in honour of Pele and the aesthetics of performance have changed.

A well-known Hawaiian hula called 'Aia lā o Pele' has been in the repertoire of most 'traditional' dance schools for many years. Indeed, it is one of the first hula kahiko (traditional dances) learned by many students of hula. I learned this dance and its music from Mary Kawena Pukui and her daughter, Patience Wiggin Bacon, in the 1970s.

\footnotetext{
2 The 1903 album also includes photographs of another Cook Island dance and a brass band.

3 The present-day spelling of this term would be ho olaulea, but the name of the film lacks the glottal stop.
} 
The origin of this text and dance is from the area of the active volcano on the island of Hawai' $i$. However, the story associated with Pele ranges widely over the Hawaiian Islands-moving from the island of Hawai' $i$ to Kaua' $i$ and back again. In recent years, Pele has become the subject of many contemporary hula, as performed at the Merrie Monarch Festival and other hula competitions, stage plays, and television presentations. I am continually surprised by how contemporary dances about Pele differ from how I learned 'Aia lā o Pele' and other dances about Pele. I decided to start with an older filmed version of the dance, so I had a baseline for comparison. This was found in Francis Haar's beautiful film, Hula Hoolaulea, in which 'Iolani Luahine performs the dance in almost the exact choreography that I learned from Pukui and Bacon (they come from the same hula tradition).

First, a few words about 'Aia lā o Pele' and Hawaiian dance in general as I learned it and as it can be seen in the Hoolaulea film. Traditional Hawaiian dance was an integrated system of poetry, rhythm, melody, and bodily movement, but the basis was poetry. The performer was a storyteller (not an actor) who conveyed the text orally and accompanied the text with movements of the body, especially the hands and arms. The shoulders and upper body usually did not make significant movements. The dances were often performed seated, and when standing, the movements of the legs and hips were essentially for timekeeping/rhythm and usually did not add to the storytelling function.

As a system of knowledge, hula is a product of action and interaction, as well as processes through which action and interaction take place. Socially and culturally constructed over time, this system of knowledge was created by, known, and essentially agreed upon by a group of people and primarily preserved in memory. Though transient, the music and movement dimensions have structured content, are sound and visual manifestations of social relations, are the subject of an elaborate aesthetic system, and can assist in understanding cultural values. The system cannot be observed; it is invisible and carried in people's heads. Existing in memory, hula can be recalled as sound and movement motifs and imagery, used to create compositions that produce social and cultural meaning in performance.

Today, hula has become an important part of Hawaiian ethnic identity, primarily conveyed at festivals and competitions. A renaissance of Hawaiian dance began in the late 1960s, and hula has played an 
important role as the visual manifestation of Hawaiian identity, and hula has become part of Hawaiian politics. The most spectacular venue for displaying and performing modern ethnic identity is during the Merrie Monarch Festival. Named after King Kalākaua, the Merrie Monarch Festival hula competition has taken place in Hilo, Hawai' $i$, each year since 1971. The competitions take place the week after Easter and are judged by a panel of seven judges, who are highly regarded members of the hula community. But, at the Merrie Monarch and other hula competitions, there is a collision of ideas over questions of tradition and innovation. While some Hawaiian dancers and choreographers feel that old hula should not be changed and that 'traditional' has the meaning of retaining various restrictions, other choreographers focus on innovation and feel that 'traditional' can also have a twenty-first-century style. Their new choreographies are often found in dances about Pele and volcanoes, and form an excellent comparison to illustrate how the aesthetics of performance have changed since the 1960 performance of 'Iolani Luahine on film.

In some new performances, dramatic stories are announced beforehand and have become dramatisations similar to Asian and Western theatre, where performers become actors rather than storytellers. In the performances, we are transported around the island of Hawai $i$, to various other islands in the archipelago, and sometimes to the homeland of Kahiki (Tahiti). The dramatic presentations engage audience members who need not have competence or knowledge of traditional Hawaiian dance or understand the Hawaiian language. To connoisseurs of traditional Hawaiian dance who value the traditional aesthetic, some of these performances have little or no association with tradition. Others, who subscribe to the newer aesthetic, feel that these new theatrical performances bridge tradition with innovation.

In a more contemporary aesthetic, encounters between two supernatural beings, such as Pele and one of her sisters, Namakaokaha'i, or between Pele and demigods may be dramatised. Costumes may be in colours that help to tell a story, and adornments may symbolise a kinolau, the many forms that a supernatural body might take. Although choreographies are built primarily from well-known Hawaiian movement motifs, other non-traditional motifs are added, such as pulling the hair of opposing dancers, open fingers, facial grimaces, quivering shoulders, and 
the incorporation of other parts of the body. Instead of all performing the same choreography, one dancer may become Pele, and skirts might be moved to become flowing lava (Kaeppler 2004).

Another concern here is where hula films/videos can be accessed. Although copies of the 16-mm film of Hoolaulea are at the Honolulu Academy of Arts in Honolulu, I have not been able to find out where the original film or the outtakes are. At one time copies of the $16-\mathrm{mm}$ film were available for purchase, but I have not found digitised versions, and it is unlikely that it will be used for study in its $16-\mathrm{mm}$ form. Further, where are the videos of the 40 years of Merrie Monarch performances? KITV television station filmed the competition in its early years, and some of the older tapes have deteriorated in storage. KITV is working with federal grant funds to restore some of these, and some are now being archived at KITV in DVD format and can be consulted under 'certain conditions', but are not easily available. KITV gave video copies to the Merrie Monarch Festival Office, but they do not have viewing facilities. Many of those tapes have probably also deteriorated, and as the technical specifications of tape formats have changed over time, many tapes can no longer be played owing to evolving technology. KITV has made highlight videos, some of which have been available for purchase (John Wray, KITV Production Manager, pers. comm.). KITV also gave to Bishop Museum some of their original 3/4-inch tapes from the 1980s, and it is likely that some Merrie Monarch materials are included. However, in this form they cannot be played, and there are no funds to transfer them to viewable copies. Even the Hawaiian collections at various branches of the University of Hawai' $i(\mathrm{UH})$ do not have copies of all the Merrie Monarch videos available for research.

Indeed, it seems that there are few places that a good corpus of hula performances on film and video can be consulted. The Hawaiian collection at Hamilton Library has viewing facilities for UH-affiliated researchers, and the Wong Audiovisual Center in Sinclair Library at UH also has viewing facilities for $\mathrm{UH}$-affiliated people. Some of these can be borrowed by individuals with UH identification cards, and Hamilton Library also has a copy of Hoolaulea for viewing.

Bishop Museum also has some viewing opportunities for film research. In addition to a viewing copy of Hoolaulea, they also have the original films by Tip Davis of 'Iolani Luahine performing in her later years. In 1976 and 1978, the State Foundation for Culture and the Arts funded 'Iolani and Hoakalei Kamau'u to travel interisland to do live performances in various 
locations. Photographer Tip Davis travelled with them to shoot 16-mm film to document the performances. These films and accompanying audiotape reels are in Bishop Museum Archives. Additional footage was shot and a rough cut was shown to Luahine before she passed on. The film was shown on television station KHET, and Davis gave all of the film from the project to Bishop Museum. However, because of family misunderstandings the film cannot be used freely. Apparently, Luahine had not signed a release, but verbally assented to the film being used for educational purposes. Kamau'u had signed a release, but her daughter asserted that she (the daughter) was the inheritor of all of Luahine's dances and will not allow showings of the film. ${ }^{4}$ Kamau' u's sons, however, disagreed and said that 'Iolani would not have agreed with this restriction since she willingly participated in all the filming, and would not have performed dances that should not have been seen by others. The unsatisfactory outcome is that Bishop Museum can show the film (but not some of the outtakes) to people who come to the archives in person to view it, but they cannot make copies. The archivists are sad about this because they feel that the film offers insights into 'Iolani's dancing and personality (DeSoto Brown and Leah Caldeira, pers. comm.). The Hawai'i State Archives also has a copy of the 16-mm film copy of Hoolaulea, but has no equipment for viewing. ${ }^{5}$

\section{Uses of archival music and dance films}

For what purposes can these twentieth-century Polynesian dance films be used? In addition to using film for ethnic identity purposes and for studies in changing aesthetics, another use of archival film is for studies of the theoretical construction of Polynesian music/dance as 'art'. The lack of historic documents that illustrate how specific artistic works influence later works has led some critics and historians to deny the status of 'works of art' to such treasures as Tahitian dance and Hawaiian hula. They have even implied that non-Western cultures do not have aesthetic systems. Archival film can demonstrate historic relationships and their influence

4 This is not accurate, however, as 'Iolani learned family dances from her great-aunt Keahi Luahine, as did Kawena Pukui and her daughter, Patience Wiggin Bacon, and they also inherited the right to pass them on (Kaeppler 1993: Chapter 4).

5 There are also DVDs available of various dance films, such as Eddie and Myrna Kamae's documentary Keepers of the Flame (2005), which includes performances by 'Iolani Luahine, Kawena Pukui, and Edith Kanakaole. 
on later works, such as the relationship of Cook Island dances in 1903 to the 1937 Tahitian tiered-platform dance and its relationship to the dance of Taha'a in 1979.

Archival film has also become important in the study of festivals (Stevenson 1998, 1999; Moulin 1996; Kaeppler 1987, 1988, 2002a). Although the study of festivals has long been important in anthropology and folklore, only recently has the exploration of festivals been expanded to include the study of the performance itself, why performance is such an important aspect of festivals, and how performances at festivals might contribute to cultural theory. Festivals take place at special times and places, and often serve to intensify societal values by bringing them into sharper focus during special events. But as the world changes, special events change along with the values they intensify. Examining festivals helps to understand values and how these values are exhibited in public presentation. In many Pacific island societies, movement sequences that originated in rituals performed in sacred spaces (or temples) were transformed from religious 'work' into 'dance'. Many of these dances have been preserved as cultural treasures, and sometimes presented as 'art'. More recently, these treasures have been presented as ethnic-identity markers in their home islands and in international festivals. Indeed, festivals have become 'rituals of identity'.

Festivals illustrate how individuals and groups want to present themselves - to themselves and to outsiders. Identity-making rituals, such as the Tahitian Heiva festival can help to explicate what has changed during transformations from the temples of old to the festival stage; how, why, and under whose authority these transformations took place; and how the aesthetics of performing have changed in Hawai' $i$ during the past 50 years.

Although I have strayed from archival film itself, my message revolves around theimportance of archival materials and their continued availability to indigenous peoples and the researchers who want to use them. A number of archives in various parts of the world have been exemplary in preserving the imprisoned films and recordings. Some archives, such as the Berlin Phonogramm-Archiv, have been especially forthcoming in sharing their treasures with indigenous and outside researchers by releasing them from captivity and using them in a variety of ways, including returning copies of these materials to their lands of origin. No doubt, the twenty-first century will continue to witness the return of the many historic treasures of sound and film now in overseas repositories to their homelands and their eventual release from imprisonment. 


\section{Acknowledgements}

I wish to thank Dr Douglas Campbell, who made the 1937 film footage, and Marian Van Tuyl Campbell, who donated the film to Bishop Museum; Bishop Museum for making the Tahiti film available to the Smithsonian Institution; and the Human Studies Film Archives at the Smithsonian for making copies of the Tahitian film footage and the video copy sent to Tahiti. I also wish to thank DeSoto Brown and Leah Caldeira, of Bishop Museum Archives; Joan Hori, formerly of Hamilton Library, University of Hawai i; Luella Kurkjians, Hawai'i State Archives; and John Wray, KITV, for information on their holdings and access to them. I also wish to thank Noenoelani Zuttermeister Lewis and Barbara B. Smith for their comments on the manuscript.

\section{References cited}

Haar, Francis. 1961. Hula Hoolaulea: Traditional Dances of Hawaii. Film. Honolulu: Honolulu Academy of Arts.

Kaeppler, Adrienne L. 1977. 'Polynesian Dance as "Airport Art".' In Asian and Pacific Dance: Selected Papers from the 1974 CORD-SEM Conference, edited by Adrienne L. Kaeppler, Judy Van Zile, and Carl Wolz, 71-84. Dance Research Annual, 8. New York: Committee on Research in Dance.

- 1987. 'Pacific Festivals and Ethnic Identity.' In Time Out of Time: Essays on the Festival, edited by Alessandro Falassi, 162-70. Albuquerque: University of New Mexico Press.

. 1988. 'Pacific Festivals and the Promotion of Identity, Politics, and Tourism.' In Come Mek Me Hol' Yu Han': The Impact of Tourism on Traditional Music, edited by Adrienne L. Kaeppler and Olive Lewin, 121-38. Kingston, Jamaica: Jamaica Memory Bank.

- 1993. Hula Pahu: Hawaiian Drum Dances. Volume 1: Ha'a and Hula Pahu: Sacred Movements. Bulletin in Anthropology, 3. Honolulu: Bishop Museum Press. 
2002a. 'Pacific Festivals of Art: Venues for Rituals of Identity.'

In 'Pacific Festivals of Arts', edited by Karen Stevenson, special issue, Pacific Arts 25: 5-19.

—. 2002b. 'The Tahitian Fête of 1937 Revisited in 1979.' In Music Archiving in the World: Papers Presented at the Conference on the Occasion of the 100th Anniversary of the Berlin Phonogramm-Archiv, edited by Gabriele Berlin and Artur Simon, 91-100. Berlin: Verlag für Wissenschaft und Bildung.

- 2004. 'Recycling Tradition: A Hawaiian Case Study.' Dance Chronicle 27 (3): 293-311. doi.org/10.1081/DNC-200033871.

—. 2016. 'Objectifying Pele as Performance, Material Culture and Cultural Landscape.' In Engaging Smithsonian Objects through Science, History, and the Arts, edited by Mary Jo Arnoldi, 90-103. Washington, DC: Smithsonian Scholarly Press.

Kaeppler, Adrienne L., and Jacob W. Love. 1998. eds. Australia and the Pacific Islands. With audio CD. The Garland Encyclopedia of World Music, 9. New York: Garland Publishing Company.

Kamae, Eddie, and Myrna Kamae. 2005. Keepers of the Flame: The Cultural Legacy of Three Hawaiian Women. DVD. Honolulu: Hawaiian Legacy Foundation.

Moulin, Jane Freeman. 1996. 'What's Mine Is Yours? Cultural Borrowing in a Pacific Context.' Contemporary Pacific 8 (1): 128-53.

Oxford University Press. 2002. The Oxford American College Dictionary. New York: G. P. Putnam's Sons.

Stevenson, Karen. 1998. 'Festivals and Identity.' In The Garland Encyclopedia of World Music, edited by Adrienne L. Kaeppler and J. W. Love, 55-57. The Garland Encyclopedia of World Music, 9. New York and London: Garland Publishing.

- 1999. 'Festivals, Identity and Performance: Tahiti and the 6th Pacific Arts Festival.' In Art and Performance in Oceania, edited by Barry Craig, Bernie Kernot, and Christopher Anderson, 29-36. Honolulu: University of Hawai'i Press. 
This text is taken from A Distinctive Voice in the Antipodes: Essays in Honour of Stephen A. Wild, edited by Kirsty Gillespie, Sally Treloyn and Don Niles, published 2017 by ANU Press, The Australian National University,

Canberra, Australia.

dx.doi.org/10.22459/DVA.07.2017.16 